\title{
BMJ Open Clinical outcomes and resource utilisation in Medicare patients with chronic liver disease: a historical cohort study
}

\author{
Zobair M Younossi, ${ }^{1,2}$ Li Zheng, ${ }^{2}$ Maria Stepanova, ${ }^{2}$ Chapy Venkatesan, ${ }^{1}$ \\ Alita Mishra ${ }^{1}$
}

To cite: Younossi ZM, Zheng L, Stepanova M, et al. Clinical outcomes and resource utilisation in Medicare patients with chronic liver disease: a historical cohort study. BMJ Open 2014;4:e004318. doi:10.1136/bmjopen-2013004318

- Prepublication history and additional material is available. To view please visit the journal (http://dx.doi.org/ 10.1136/bmjopen-2013004318).

Received 23 October 2013 Revised 7 April 2014 Accepted 24 April 2014

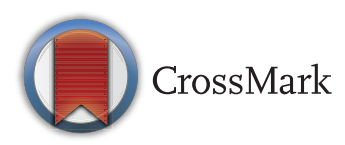

${ }^{1}$ Department of Medicine, Inova Fairfax Hospital, Falls Church, Virginia, USA

${ }^{2}$ Betty and Guy Beatty Center for Integrated Research, Inova Health System, Falls Church, Virginia, USA

Correspondence to Dr Zobair M Younossi; zobair.younossi@inova.org

\section{ABSTRACT}

Objective: The aim of this study is to assess recent trends in health resource utilisation and patient outcomes of Medicare beneficiaries with chronic liver disease (CLD).

Setting: Liver-related mortality is the 10th leading cause of death in the USA, and hepatitis C virus (HCV) and obesity-related non-alcoholic fatty liver disease are the major causes of CLD. As the US population ages and becomes more obese, the impact of CLD is expected to become more prominent for the Medicare population.

Participants: This is a retrospective cohort study of Medicare beneficiaries with a diagnosis of CLD based on inpatient ( $\mathrm{N}=21$ 576; 14977 unique patients) and outpatient ( $\mathrm{N}=515$ 990; 244196 patients) claims from 2005 to 2010.

Primary and secondary outcome measures: The study outcomes included hospital length of stay (LOS) and inpatient mortality as well as inpatient and outpatient inflation-adjusted payments.

Results: Between 2005 and 2010, there was an annual decrease in LOS of $3.17 \%$ for CLD-related hospitalisations. Risk-adjusted in-hospital mortality decreased (OR $0.90,95 \% \mathrm{Cl} 0.87$ to 0.94 ), while short-term postdischarge mortality remained stable (1.00, 0.98 to 1.03). Inpatient per-claim payment increased from \$11 769 in 2005 to $\$ 12347$ in 2010 $(p=0.0006)$. Similarly, the average yearly payments for outpatient care increased from $\$ 366$ to $\$ 404$ $(p<0.0001)$. This change in payment was observed together with a consistent decrease in the proportion of beneficiary-paid amount $(25.4-20 \%, p<0.0001)$ as opposed to Medicare-paid amount $(73.1-80 \%$, $p<0.0001$ ). The major predictors of higher outpatient payments were younger age, Asian race or Hispanic ethnicity, living in California, and having more diagnoses and outpatient procedures per claim. The predictors of inpatient spending also included younger age, location and the number of inpatient procedures.

Conclusions: Length of inpatient stay and inpatient mortality among Medicare beneficiaries with CLD decreased, while inpatient and outpatient spending increased.

\section{Strengths and limitations of this study}

- First study assessing recent trend in health resource utilisation by Medicare beneficiaries with chronic liver disease.

- Used a representative sample of the national Medicare population.

- Included inpatient and outpatient claims.

- Identified demographic and clinical factors associated with resource utilisation and short-term mortality.

- Exact service dates were not available, making it impossible to conduct survival analysis to account for variability in length of postdischarge follow-up.

- Postdischarge mortality may be underestimated due to some unvalidated death dates.

- Unmeasured confounders may exist in a retrospective cohort study.

- Could not determine whether patients sought care outside Medicare.

\section{INTRODUCTION}

Chronic liver disease (CLD) is a major cause of mortality and morbidity worldwide. ${ }^{1-5}$ In the USA, liver-related mortality is the 10th leading cause of death with hepatitis $\mathrm{C}$ virus (HCV) and obesity-related non-alcoholic fatty liver disease (NAFLD) being the major causes of CLD. ${ }^{1-4} 6-9$

Medicare is a US government-sponsored health insurance programme that guarantees access to healthcare for US residents 65 years of age or older, younger individuals with disabilities, those with end-stage renal disease (ESRD) or Lou Gehrig's disease. In addition to Medicare's payment, enrollees are responsible for a number of out-of-pocket payments including deductibles and coinsurance as well as payment for uncovered services; however, supplemental insurance may be used to cover a certain proportion of the 
beneficiary-paid amount. In 2010, Medicare made up $23 \%$ of all personal healthcare spending in the USA. ${ }^{10}$

In patients with CLD, age is known to be associated with adverse outcomes. ${ }^{7} 8$ As the US population ages and becomes more obese, the impact of CLD is expected to become more prominent for the Medicare population. ${ }^{6} 9$ The cohort of baby boomers (Americans born between 1946 and 1964) also has a large proportion of HCV infection and is currently approaching the age of eligibility for Medicare, adding to the growing burden of CLD. In this context, recent reports by The Institute of Medicine emphasised the need for a national prevention and control strategy for patients with viral hepatitis-associated CLD. ${ }^{4}$

To date, Medicare resource utilisation related to CLD has not been fully assessed. The recent healthcare reform legislation will be impacting what Medicare spends and how hospitals are reimbursed. The aim of this study was to assess recent trends in inpatient and outpatient Medicare spending related to CLD.

\section{METHODS}

\section{Data source}

This is a retrospective cohort study of Medicare claims. We analysed Medicare inpatient and outpatient files from 2005 to 2010 submitted by outpatient and inpatient providers for reimbursement of treatment and facility costs. For each year, we obtained a $5 \%$ random sample of Medicare beneficiaries that were included in the Denominator Files provided to us by the Centers for Medicare \& Medicaid Services (CMS) in the format of Limited Data Set (LDS) Standard Analytic Files. Each year, for the sampled beneficiaries, all inpatient and outpatient claims for the study years were included.

The inpatient file contains inpatient hospital encounters incurred during the study period. Each record represents a single hospital claim which includes a unique patient identifier, basic demographics, admission type and discharge status, International Classification of Diseases, 9th Revision, Clinical Modification (ICD-9-CM) diagnosis and procedure codes, other conditions related to the Medicare bill that include various claim-related information such as being homeless, unemployed, military, student, or over 100 years old, as well as hospital charges, Medicare reimbursement amount and payment from the patient and another insurance.

In outpatient files, each record represented a single outpatient claim. The parameters used for the study included Medicare billing data with a unique patient identifier which was used to link data for each beneficiary across all Medicare files, the last day on the billing statement of covered services rendered to the beneficiary, a list of up to 10 diagnoses and 6 outpatient ICD-9 procedures, total facility charges, Medicare reimbursement amount and payments from patient and other insurance providers.
The denominator file included Medicare beneficiary enrollment, demographics (age, gender, ethnicity, the region of residence) and short-term mortality information. No data elements that might permit identification of beneficiaries were left in the CLD files.

\section{Study population}

The following ICD-9-CM codes were used to establish the diagnosis of CLD in inpatient and outpatient claims: viral hepatitis $(070.0,070.1,070.20-070.23,070.30$ 070.33, 070.41-070.44, 070.49, 070.51-070.54, 070.59, $070.6,070.70,070.71,070.9)$, liver disorders of iron and copper metabolism (275.0, 275.01-275.03, 275.09, 275.1), oesophageal varices with or without bleeding (456.0, 456.1, 456.20, 456.21), CLD and cirrhosis (571.0-571.3, 571.40-571.42, 571.49, 571.5, 571.6, 571.8, 571.9), sequelae of CLD such as hepatic coma, portal hypertension and hepatorenal syndrome (572.2-572.4, 572.8), other chronic disorders of liver and biliary tract (573.3, 573.5, 573.8, 576.1, 576.8), cholestatic jaundice (782.4), hepatomegaly (789.1), ascites (789.5), abnormal liver scan/function study (794.8) and indicators of CLD coded as factors and external causes (E947.9, V02.60, V02.61, V02.62, V02.69, V42.7). For inpatient visits, a claim was included in the study only if the principal diagnosis for that claim was CLD related. Outpatient analysis included claims-related CLD identified from either principle or secondary diagnoses.

Patient baseline characteristics were derived from Medicare denominator file, which included age categories at admission, gender, race/ethnicity, ESRD status, residence (Northeast, South, Midwest, West and California), discharge disposition type, continued care, hospice status and inpatient death. Comorbidities scores were derived from up to nine secondary diagnosis codes using Deyo-modification of the Charlson score developed for claims data analysis. ${ }^{11}$ The total number of diagnoses and total number of procedures in each record were also included in the analysis (might exceed 10 diagnoses or 6 procedures that were given explicitly).

\section{Inpatient outcomes}

Resource utilisation and short-term mortality outcomes were assessed. Resource utilisation parameters included length of stay (LOS) and total payments as well as the proportion of Medicare spending and of beneficiarypaid amount. Total payments for patient services in each claim were calculated as the sum of Medicare reimbursement amount, primary insurance payment, beneficiarypaid amounts (copay, deductibles and coinsurance). The annual percent changes of Consumer Price Indexes (CPI) for Medical care were used to adjust the annual payments, to the dollars of 2010.

LOS was defined as the number of full days a patient stays in the hospital. Since admission and discharge dates were not provided in the data, LOS was calculated as the total number of days of care in each claim, which included the number of days of care that were 
chargeable and the number of days of care that were not chargeable to Medicare facility utilisation. If a patient was admitted and discharged on the same day, LOS was counted as 1 day. According to Medicare policy, patients need to pay a certain amount of coinsurance for a LOS over 60 days, and no coinsurance for LOS 160 days. To remove the potential effect of coinsurance on LOS, cases with LOS over 60 days were dismissed from analysis.

Short-term mortality outcomes were evaluated for each calendar year. In the case of multiple hospitalisations within a calendar year, the most recent claim was designated as the index event. If a patient was hospitalised for CLD in multiple calendar years, he was counted as new patient for each year. In-hospital mortality was defined as an in-hospital record with discharge status of 'Dead', regardless of cause or LOS. Short-term post-discharge mortality was defined as a death from any cause after hospital discharge, after excluding patients who died in hospital. We determined short-term postdischarge mortality based on the death date recorded in the Medicare denominator file. The period of follow-up for short-term postdischarge mortality was the end of March of the year following patient's index discharge.

\section{Outpatient outcomes}

The resource utilisation parameters included total payments, Medicare spending and the proportion of beneficiary-paid amount. Total per-claim payment was the sum of Medicare reimbursement amount, primary insurance payment and the beneficiary-paid amount which included all applicable copayments, deductibles and coinsurance. If more than one outpatient claim was reported for a patient in a given year, then, for that patient in that year, the resource utilisation parameters were added up, and the total yearly resource utilisation, together with the average proportion of beneficiary-paid amount in per cent of total payments, was calculated.

\section{Statistical analysis}

We described the baseline characteristics of the study population by presenting frequencies for categorical variables and mean $\pm \mathrm{SD}$ for continuous variables. Mean LOS, hospital charge and total payments for each claim were calculated. Unadjusted rates of all-cause in-hospital mortality and postdischarge mortality were estimated. In both analyses, all available clinical and demographic parameters were compared across the study years to identify parameters that changed significantly over time, using $\chi^{2}$ test for binary or categorical parameters (age, gender, race, mortality, etc) and non-parametric Kruskal-Wallis Test for continuous parameters (LOS, hospital charge, Charlson score, number of diagnosis, number of procedures).

Multivariable regression analyses were run to assess the independent association of inpatient and outpatient resource utilisation and patients' clinicodemographics characteristics that were used as potential predictors.
LOS and total payments were found to be skewed to the right in a non-normal distribution and therefore were analysed using generalised linear model with a $\gamma$ error distribution and a log-link function. The adjusted relationship between predictors and resource utilisation were estimated using $\beta$ coefficients from these models, which were exponentiated to yield a percentage change in the outcomes associated with each predictor.

Multivariate logistic regression analysis was performed on in-hospital mortality and short-term postdischarge mortality. The association between a mortality predictor and an outcome was analysed with the $\chi^{2}$ test, which was used to compare the risk-adjusted rate of mortality among those with and those without the risk factor. OR was used to estimate the adjusted association between each predictor and mortality. Significance tests and CIs were based on a two-sided $95 \%$ confidence level.

\section{RESULTS}

\section{Demographics and outcomes for inpatients with CLD}

The analysis included 21576 hospitalisations with a principal diagnosis of CLD during 2005-2010 for a total of 14977 patients. The annual number of claims ranged from minimum of 3475 in 2008 to maximum of 3698 in 2005 (tables 1 and 2, see online supplementary table S1). The annual per cent of rehospitalisations was about 23\%. The most common primary diagnoses were hepatic encephalopathy (25.10\%), non-alcoholic cirrhosis of liver $(18.01 \%)$, alcoholic cirrhosis of liver $(15.16 \%)$ and sclerosing cholangitis $(6.17 \%)$.

During the study period, the observed in-hospital mortality decreased from $11.81 \%$ to $8.38 \%$ ( $p<0.001$ ), postdischarge mortality decreased from $36.37 \%$ to $33.82 \%$ $(p=0.0099)$, the average number of diagnoses per claim increased from 7.92 to $8.64 \quad(\mathrm{p}<0.001)$ and Charlson score increased $(1.31-1.36 ; \mathrm{p}<0.001)$. The proportion of patients discharged to home decreased, while the proportion discharged to hospice or continued care increased.

The number of admissions, diagnoses and procedures and male gender were independently associated with increased risk for in-hospital mortality. Independent predictors of short-term postdischarge mortality were discharge disposition, number of admissions, Charlson score, gender and LOS during hospitalisation. Age appeared to be a stronger predictor of postdischarge mortality than in-hospital mortality. The adjusted in-hospital mortality rate decreased between 2005 and 2010, while the adjusted postdischarge mortality rate remained stable. Furthermore, there were regional and racial variations in postdischarge mortality using the standard reference categories (table 3).

\section{Inpatient spending for Medicare beneficiaries with CLD}

The proportion of CLD-related inpatient spending in the total inpatient spending for Medicare beneficiaries increased from $7.70 \%$ in 2005 to $8.84 \%$ in 2008 and decreased to $7.66 \%$ in 2010 . Total payments increased 
Table 1 Clinicodemographic characteristics of Medicare beneficiaries who sought inpatient and outpatient care in 2005-2010

\begin{tabular}{|c|c|c|c|c|c|c|}
\hline \multirow[b]{2}{*}{ Characteristics } & \multicolumn{3}{|l|}{ Inpatient } & \multicolumn{3}{|l|}{ Outpatient } \\
\hline & 2005 & 2010 & p Value* & 2005 & 2010 & p Value ${ }^{\star}$ \\
\hline Number of patients & 2582 & 2458 & & 39885 & 44546 & \\
\hline Number of claims & 3698 & 3680 & & 83866 & 94309 & \\
\hline Rehospitalisations, \% & 24.20 & 25.83 & 0.0653 & NA & NA & \\
\hline Number of diagnoses & $7.92 \pm 1.73$ & $8.64 \pm 1.31$ & $<0.0001$ & $3.55 \pm 2.11$ & $4.32 \pm 2.39$ & $<0.0001$ \\
\hline Number of procedures & $1.59 \pm 1.75$ & $1.67 \pm 1.79$ & 0.2554 & $0.01 \pm 0.16$ & $0.01 \pm 0.18$ & NS \\
\hline Charlson score & $1.31 \pm 1.58$ & $1.36 \pm 1.67$ & $<0.0001$ & $1.25 \pm 1.46$ & $1.43 \pm 1.50$ & $<0.0001$ \\
\hline \multicolumn{7}{|l|}{ Age, $\%$} \\
\hline$<65$ & 38.18 & 42.47 & $<0.0001$ & 30.48 & 34.33 & $<0.0001$ \\
\hline $65-69$ & 15.87 & 19.62 & $<0.0001$ & 20.65 & 21.46 & 0.0055 \\
\hline $70-74$ & 16.01 & 12.64 & $<0.0001$ & 17.66 & 16.52 & 0.0006 \\
\hline $75-79$ & 13.28 & 8.89 & $<0.0001$ & 15.03 & 12.35 & $<0.0001$ \\
\hline $80-84$ & 9.19 & 8.40 & 0.0166 & 9.70 & 8.88 & $<0.0001$ \\
\hline 85 and over & 7.46 & 7.99 & 0.1107 & 6.49 & 6.47 & NS \\
\hline \multicolumn{7}{|l|}{ Race, \% } \\
\hline White & 81.18 & 79.24 & 0.0162 & 81.85 & 80.58 & $<0.0001$ \\
\hline Black & 10.25 & 10.84 & 0.2218 & 10.68 & 11.71 & $<0.0001$ \\
\hline Hispanic & 4.57 & 5.33 & 0.1124 & 2.48 & 2.70 & NS \\
\hline Other & 4.00 & 4.59 & 0.0428 & 2.71 & 2.09 & $<0.0001$ \\
\hline Male gender & 53.95 & 54.35 & 0.0836 & 45.75 & 46.04 & NS \\
\hline End-stage renal disease & 3.49 & 6.11 & $<0.0001$ & 3.48 & 3.52 & NS \\
\hline \multicolumn{7}{|l|}{ Discharge status, \% } \\
\hline Home & 52.52 & 49.57 & $<0.0001$ & NA & NA & NA \\
\hline Continued care & 36.78 & 39.78 & $<0.0001$ & NA & NA & NA \\
\hline Hospice & 4.25 & 5.08 & $<0.0001$ & NA & NA & NA \\
\hline Died & 6.46 & 5.57 & $<0.0001$ & NA & NA & NA \\
\hline \multicolumn{7}{|l|}{ Region, \% } \\
\hline Northeast & 16.88 & 21.17 & 0.1323 & 19.96 & 19.25 & 0.0045 \\
\hline South & 34.86 & 39.44 & $<0.0001$ & 26.26 & 25.45 & 0.0002 \\
\hline Midwest & 18.85 & 23.25 & 0.0044 & 36.50 & 37.69 & 0.0007 \\
\hline West & 7.23 & 8.31 & 0.0025 & 8.98 & 8.83 & NS \\
\hline California & 7.77 & 9.49 & $<0.0001$ & 8.29 & 8.78 & $<0.0001$ \\
\hline
\end{tabular}

${ }^{*} p$ Value indicates the significance of change over the study years.

NA, not applicable; NS, not significant.

from $\$ 11769$ to $\$ 12347$ per claim $(\mathrm{p}<0.001)$, average LOS decreased from 6.02 to 5.74 days $(\mathrm{p}<0.001)$. Independent predictors of increases in LOS included black or Hispanic race/ethnicity, number of diagnoses and procedures, died in hospital or disposition other than to home. Independent predictors of increases in total payments were similar. The adjusted total payments also increased with LOS and across the study years (table 4).

\section{Demographics and outcomes for outpatients with CLD}

A total of 515990 CLD-related outpatient claims for 244196 unique Medicare beneficiaries with CLD were included for the study period. Of those, $42.5 \%$ were the claims with CLD as a primary diagnosis (table 1, see online supplementary table S2).

The number of patients with at least one CLD claim ranged from the minimum of 38485 in 2008 to the maximum of 44546 in 2010, representing approximately 770 000-890000 Medicare beneficiaries with CLD nationwide. The most prevalent CLD diagnosis on outpatient claims was non-alcoholic cirrhosis of liver (ICD-9 code 571.5) that was present in 14\% outpatient claims in patients with CLD. The most prevalent primary diagnoses on claims where CLD was a secondary diagnosis were abdominal pain (789.00), type II diabetes mellitus without mention of complication (250.00), and ESRD (585.6) each present 3.3\% of claims with CLD.

Similarly to the inpatient population, the proportion of patients who were less than 65 years old increased from $30.5 \%$ in 2005 to $34.3 \%$ in $2010 \quad(p<0.0001)$. Ethnic profile of a Medicare beneficiary with CLD also shifted towards a lower proportion of Caucasians: from $81.94 \%$ to $80.58 \%(p<0.0001)$. The proportion of patients living in the South region also slightly increased, while the gender distribution of Medicare beneficiaries with CLD did not change with $45.8-46.5 \%$ of patients being men (table 1 ).

Outpatient spending for Medicare beneficiaries with CLD The proportion of total outpatient spending for claims with CLD in the total outpatient spending for Medicare 
Table 2 Resource utilisation and mortality outcomes for Medicare beneficiaries with CLD who sought inpatient care in 2005-2010

\begin{tabular}{|c|c|c|c|c|c|c|c|}
\hline & 2005 & 2006 & 2007 & 2008 & 2009 & 2010 & p Value \\
\hline Length of stay, days & $6.02 \pm 5.61$ & $5.92 \pm 5.65$ & $5.86 \pm 5.40$ & $5.78 \pm 5.54$ & $5.61 \pm 5.45$ & $5.74 \pm 5.57$ & 0.0001 \\
\hline Mean \pm SD & $4(3,7)$ & $4(3,7)$ & $4(3,7)$ & $4(3,7)$ & $4(2,7)$ & $4(3,7)$ & \\
\hline \multicolumn{8}{|l|}{ Median (IQR) } \\
\hline Payment by patient, $\$$ & $650 \pm 782$ & $649 \pm 695$ & $650 \pm 762$ & $661 \pm 796$ & $661 \pm 802$ & $626 \pm 758$ & $<0.0001$ \\
\hline Mean \pm SD & $1096(0-1096)$ & $1100(0-1100)$ & $1098(0-1098)$ & $1093(0-1093)$ & $1104(0-1104)$ & $1100(0-1100)$ & \\
\hline \multicolumn{8}{|l|}{ Median (IQR) } \\
\hline Payment by patient, \% & $7.70 \pm 9.20$ & $7.64 \pm 8.77$ & $8.54 \pm 12.67$ & $8.84 \pm 13.33$ & $8.18 \pm 10.16$ & $7.66 \pm 9.48$ & 0.0507 \\
\hline Mean \pm SD & $7.66(0-13.36)$ & $7.55(0-13.38)$ & $7.32(0-13.59)$ & $7.38(0-13.71)$ & $6.20(0-13.80)$ & $4.38(0-12.75)$ & \\
\hline \multicolumn{8}{|l|}{ Median (IQR) } \\
\hline Payment by Medicare, $\$$ & $10542 \pm 14023$ & $10435 \pm 13085$ & $9817 \pm 11768$ & $10159 \pm 14975$ & $9956 \pm 12547$ & $10765 \pm 13779$ & $<0.0001$ \\
\hline Mean $\pm S D$ & 7952 (6581-9962) & 7909 (6568-9938) & 7667 (6268-9638) & $7743(5749-10$ 129) & 7789 (4996-10 572) & 8482 (5194-11 326) & \\
\hline \multicolumn{8}{|l|}{ Median (IQR) } \\
\hline Payment by Medicare, \% & $89.52 \pm 17.71$ & $89.88 \pm 16.90$ & $87.65 \pm 21.65$ & $87.20 \pm 22.28$ & $88.10 \pm 20.23$ & $89.04 \pm 19.16$ & 0.0011 \\
\hline Mean $\pm S D$ & $91.29(86.34-100.00)$ & $91.41(86.26-100.00)$ & $91.01(85.79-100.00)$ & $91.18(85.10-100.00)$ & $92 . .29(84.21-100.00)$ & $93.75(85.12-100.00)$ & \\
\hline \multicolumn{8}{|l|}{ Median (IQR) } \\
\hline Total payment, \$ of 2010 & $11769 \pm 15864$ & $11623 \pm 14745$ & $11652 \pm 25393$ & $11711 \pm 18912$ & $11916 \pm 16045$ & $12347 \pm 17641$ & 0.0006 \\
\hline Mean \pm SD & $8596(7485-10748)$ & $8522(7448-10516)$ & $8382(7187-10486)$ & $8584(6623-11013)$ & $9173(5985-11779)$ & 9478 (5932-12 192) & \\
\hline \multicolumn{8}{|l|}{ Median (IQR) } \\
\hline In-hospital mortality rate, $\%$ & 8.38 & 8.89 & 8.14 & 8.71 & 9.86 & 11.81 & $<0.0001$ \\
\hline Short-term postdischarge mortality, \%* & 36.37 & 34.21 & 34.12 & 35.00 & 30.91 & 33.82 & 0.0099 \\
\hline
\end{tabular}

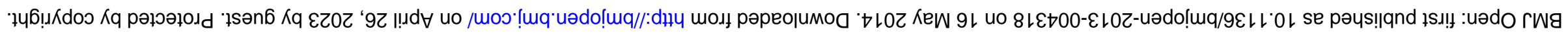


Table 3 Predictors of in-hospital mortality and overall postdischarge mortality in Medicare beneficiaries hospitalised for CLD in 2005-2010*

\begin{tabular}{|c|c|c|}
\hline Predictors & $\begin{array}{l}\text { In-hospital mortality } \\
\text { OR }(95 \% \mathrm{CI})\end{array}$ & $\begin{array}{l}\text { Postdischarge mortality† } \\
\text { OR }(95 \% \mathrm{Cl})\end{array}$ \\
\hline \multicolumn{3}{|l|}{ Age } \\
\hline $65-69$ & Ref & Ref \\
\hline$<65$ & $0.83(0.69$ to 0.99$)$ & $0.83(0.72$ to 0.94$)$ \\
\hline $70-74$ & $1.06(0.85$ to 1.31$)$ & $1.16(0.99$ to 1.35$)$ \\
\hline $75-79$ & $1.28(1.03$ to 1.60$)$ & 1.33 (1.13 to 1.56$)$ \\
\hline $80-84$ & 0.91 (0.71 to 1.18$)$ & $1.23(1.04$ to 1.46$)$ \\
\hline 85 and over & $0.92(0.70$ to 1.21$)$ & 1.51 (1.27 to 1.80$)$ \\
\hline \multicolumn{3}{|l|}{ Gender } \\
\hline Female & Ref & Ref \\
\hline Male & $1.27(1.11$ to 1.44$)$ & $1.34(1.22$ to 1.46$)$ \\
\hline \multicolumn{3}{|l|}{ Race } \\
\hline White & Ref & Ref \\
\hline Black & $1.18(0.96$ to 1.44$)$ & $0.81(0.70$ to 0.95$)$ \\
\hline Hispanic & $0.74(0.52$ to 1.04$)$ & 0.91 (0.73 to 1.13$)$ \\
\hline Other & $1.11(0.82$ to 1.51$)$ & 0.79 (0.63 to 0.99$)$ \\
\hline \multicolumn{3}{|l|}{ ESRD } \\
\hline No & Ref & Ref \\
\hline Yes & $0.73(0.55$ to 0.98$)$ & $1.14(0.93$ to 1.40$)$ \\
\hline \multicolumn{3}{|l|}{ Number of admissions } \\
\hline 1 & Ref & Ref \\
\hline$\geq 2$ & 1.50 (1.31 to 1.73$)$ & $1.62(1.46$ to 1.80$)$ \\
\hline \multicolumn{3}{|l|}{ Discharge destination } \\
\hline Home & NA & Ref \\
\hline Continued care & NA & 2.51 (2.29 to 2.76 ) \\
\hline Hospice & NA & 44.98 (33.0161.28) \\
\hline \multicolumn{3}{|l|}{ Region } \\
\hline Northeast & Ref & Ref \\
\hline South & $0.95(0.81$ to 1.13$)$ & $1.27(1.12$ to 1.43$)$ \\
\hline Midwest & 0.79 (0.65 to 0.96$)$ & $1.10(0.96$ to 1.26$)$ \\
\hline West & $0.84(0.65$ to 1.10$)$ & $1.33(1.11$ to 1.60$)$ \\
\hline California & 0.95 (0.74 to 1.22$)$ & $1.23(1.02$ to 1.47$)$ \\
\hline Calendar year & 0.90 (0.87 to 0.94$)$ & $1.00(0.98$ to 1.03$)$ \\
\hline Number of diagnosis & 1.24 (1.17 to 1.32$)$ & 1.06 (1.03 to 1.09$)$ \\
\hline Number of procedures & $1.36(1.31$ to 1.41$)$ & 0.98 (0.96 to 1.01$)$ \\
\hline Charlson score & 1.01 (0.98 to 1.05$)$ & 1.24 (1.21 to 1.28$)$ \\
\hline LOS & 1.01 (1.00 to 1.02$)$ & 1.02 (1.01 to 1.03$)$ \\
\hline
\end{tabular}

beneficiaries decreased from $1.38 \%$ in 2005 to $1.34 \%$ in 2010 (tables 5 and 6). The average number of claims per patient per year did not change during the study period remaining at the level of approximately 2.10-2.12 claims per year $(\mathrm{p}=0.56)$. Per-patient yearly total payment as well as yearly payment by Medicare and the proportion of Medicare's responsibility all increased over time (all $\mathrm{p}<0.0001)$. At the same time, the average payment by a patient and the proportion of a beneficiary-paid amount decreased between 2005 and 2010 (both $\mathrm{p}<0.001$; table 5).

In multivariate analysis, total payments were found to be decreasing over the study period by $-1.66 \%$ (95\% CI $-1.98 \%$ to $-1.34 \%)$ per calendar year. The average number of diagnoses per claim and the number of outpatient procedures per year were both independently associated with total payments (table 6). However, after ESRD, being in the youngest age group (less than 65 years old) was the most important predictor of payments $(+50.2 \%(+46.3-54.3 \%))$, likely due to the disability-related Medicare eligibility requirements for such patients. Also, there were racial and geographic variations in payments; in particular, being Asian or Hispanic were independent predictors of higher total payments in comparison to the reference Caucasians, while being African-American was associated with lower payments (table 6). Finally, the reference Northeast location was associated with the lowest payments in comparison to all other locations (table 6). 
Table 4 Predictors of LOS, hospital charge and total payment of hospitalisations of Medicare beneficiaries for CLD in 2005$2010^{*}$

\begin{tabular}{|c|c|c|}
\hline Predictors & $\begin{array}{l}\text { LOS increase } \\
\text { Per cent }(95 \% \mathrm{Cl})\end{array}$ & $\begin{array}{l}\text { Total payment increase } \\
\text { Per cent }(95 \% \mathrm{Cl})\end{array}$ \\
\hline \multicolumn{3}{|l|}{ Age } \\
\hline $65-69$ & Ref & Ref \\
\hline$<65$ & $-0.77(-3.45$ to 1.90$)$ & $-2.00(-4.44$ to 0.43$)$ \\
\hline $70-74$ & $-3.44(-6.72$ to -0.16$)$ & $-5.23(-8.22$ to -2.24$)$ \\
\hline $75-79$ & $-0.16(-3.73$ to 3.41$)$ & $-3.94(-7.20$ to -0.69$)$ \\
\hline 80-84 & $1.03(-2.83$ to 4.89$)$ & $-3.21(-6.73$ to 0.31$)$ \\
\hline 85 and over & $-0.77(-3.45$ to 1.90$)$ & $-0.37(-4.16$ to 3.42$)$ \\
\hline \multicolumn{3}{|l|}{ Gender } \\
\hline Female & Ref & Ref \\
\hline Male & $-4.63(-6.53$ to -2.72$)$ & $1.11(-0.63$ to 2.85$)$ \\
\hline \multicolumn{3}{|l|}{ Race } \\
\hline White & Ref & Ref \\
\hline Black & 9.57 (6.42 to 12.73$)$ & 4.82 (1.94 to 7.70$)$ \\
\hline Hispanic & $11.36(6.92$ to 5.80$)$ & $12.67(8.62$ to 16.71$)$ \\
\hline Other & $1.90(-2.76$ to 6.55$)$ & $1.58(-2.66$ to 5.82$)$ \\
\hline \multicolumn{3}{|l|}{ ESRD } \\
\hline No & Ref & Ref \\
\hline Yes & $2.23(-2.19$ to 6.65$)$ & $-5.86(-9.90$ to -1.82$)$ \\
\hline \multicolumn{3}{|l|}{ Discharge destination } \\
\hline Home & Ref & Ref \\
\hline Continued care & 35.39 (33.31 to 37.46 ) & $0.53(-1.39$ to 2.45$)$ \\
\hline Hospice & 37.42 (32.67 to 42.17 ) & $-1.42(-5.77$ to 2.94$)$ \\
\hline Died & 25.95 (21.96 to 29.94$)$ & 8.07 (4.44 to 1.69$)$ \\
\hline \multicolumn{3}{|l|}{ Region } \\
\hline Northeast & Ref & Ref \\
\hline South & $-4.36(-6.94$ to -1.79$)$ & $-16.68(-19.03$ to -14.33$)$ \\
\hline Midwest & $-12.18(-15.08$ to -9.28$)$ & $-23.40(-26.05$ to -20.75$)$ \\
\hline West & $-13.82(-17.71$ to -9.94$)$ & $-12.59(-16.12$ to -9.05$)$ \\
\hline California & $-9.23(-13.02$ to -5.44$)$ & 42.62 (39.16 to 46.08$)$ \\
\hline Calendar year & $-3.17(-3.68$ to -2.66$)$ & 3.08 (2.61 to 3.54$)$ \\
\hline Number of diagnosis & 9.34 (8.70 to 9.98$)$ & $3.72(3.13$ to 4.30$)$ \\
\hline Number of procedures & 17.70 (17.15 to 18.25$)$ & 19.51 (18.95 to 20.07 ) \\
\hline Charlson score & $-1.36(-1.96$ to -0.77$)$ & $-0.47(-1.01$ to 0.08$)$ \\
\hline LOS & NA & 9.02 (8.80 to 9.24$)$ \\
\hline
\end{tabular}

\section{DISCUSSION}

This is the first study to report inpatient and outpatient clinical outcomes and Medicare resource utilisation for patients with CLD. The majority of CLD primary diagnoses on inpatient claims were hepatic encephalopathy and cirrhosis. Interestingly, the Medicare population with ESRD and younger than 65 are becoming a larger portion of this cohort, Although the observed increase in the number of diagnoses per claim and Charlson index may be due to the CLD population becoming more complex with more comorbidities and related conditions, prior reports suggest that such changes might also be explained by the documentation and coding practices. $^{12}$

The risk-adjusted analysis showed that in-hospital mortality and LOS decreased. The potential reasons for a decrease in inpatient mortality include improvements in quality, efficiency of care delivery and increasing use of hospice services. ${ }^{13} 14$ while the decrease in the LOS may also be due to changes in payment arrangements and discharge practices. In fact, it is possible the recent focus on 'hospital efficiency' has moved a number of patients with CLD who were previously cared for in the inpatient setting, to the outpatient arena. This may have resulted in a decrease in inpatient LOS or even mortality but an increase in disease severity in the outpatient setting.

After adjusting for inflation, total payments to hospitals for inpatient services significantly increased. As expected, independent predictors of payments and LOS were similar. Of note, minorities experienced higher payments and LOS and could be another target for better allocation of resources. The fact that discharges to extended care facilities and inpatient deaths were associated with higher inpatient resource utilisation is consistent with the notion that patients who are at highest risk for mortality consume the greatest portion of the 
ก

กิ่ ิิ

1 워

م

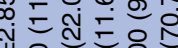

으 닌

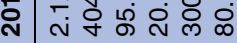

ஸి

○்

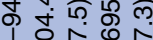

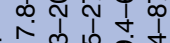

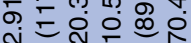

+ $\infty$ 둔

กิส

ฟั

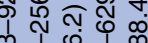

m 100

กิ

$\dot{m} \sim 0$ ○

\begin{tabular}{|c|c|}
\hline Predictors & $\begin{array}{l}\text { Payment increase, } \\
\%(95 \% \mathrm{Cl})^{\star}\end{array}$ \\
\hline Calendar year & $-1.66(-1.98$ to -1.34$)$ \\
\hline \multicolumn{2}{|l|}{ Age } \\
\hline$<65$ & 50.24 (46.30 to 54.27 ) \\
\hline $65-69$ & 33.89 (30.27 to 37.62$)$ \\
\hline $70-74$ & 29.15 (25.57 to 32.83 ) \\
\hline $75-79$ & 22.80 (19.29 to 26.41$)$ \\
\hline 80-84 & 13.86 (10.39 to 17.44$)$ \\
\hline $85+$ & Reference \\
\hline Male & 3.75 (2.48 to 5.04$)$ \\
\hline Caucasian & Reference \\
\hline Black & $-5.21(-7.10$ to -3.29$)$ \\
\hline Hispanic & 8.74 (4.55 to 13.10$)$ \\
\hline Asian & 12.22 (7.19 to 17.49$)$ \\
\hline ESRD & $120.67(113.32$ to 128.27$)$ \\
\hline \multicolumn{2}{|l|}{ Location } \\
\hline Northeast & Reference \\
\hline Midwest & 8.56 (6.60 to 10.56$)$ \\
\hline South & 6.18 (4.38 to 8.00$)$ \\
\hline West & 20.99 (18.04 to 24.01$)$ \\
\hline California & 9.07 (6.34 to 11.86$)$ \\
\hline $\begin{array}{l}\text { The number of diagnoses per } \\
\text { claim, per } \mathrm{dx}\end{array}$ & 25.45 (25.11 to 25.80$)$ \\
\hline $\begin{array}{l}\text { The number of outpatient } \\
\text { procedures, per procedure }\end{array}$ & 31.04 (26.60 to 35.64$)$ \\
\hline
\end{tabular}

healthcare resources. ${ }^{15}{ }^{16}$ It has been previously reported that Hispanic patients with CLD (especially NAFLD) are at higher risk for adverse outcome such as cirrhosis and HCC which this study also corroborates as Hispanic ethnicity is independently associated with resource utilisation. ${ }^{69}$

In the outpatient Medicare population, chronic hepatitis $\mathrm{C}$ cirrhosis, abnormal liver imaging and NAFLD were the most common CLD diagnoses with approximately half of claims with the diagnosis of CLD had one listed as a primary diagnosis. Once again, the proportion of patients younger than 65 years old and disability eligible increased. As payments from Medicare and proportion of Medicare's responsibility increased, the beneficiary-paid amount decreased. Racial and geographic variations in payment were again observed. Our study also showed that younger age was the most important independent predictor of Medicare spending. This is consistent with the fact that younger patients with CLD who qualify for Medicare can only be enrolled due to their disability or other chronic condition such as ESRD. ${ }^{17}{ }^{18}$ Furthermore, we expect that the rate of patients with HCV will continue to increase as a result of the CDC's current guidelines which recommend screening all patients between the ages of 45 and 65 regardless of risk factors for $\mathrm{HCV}^{19}$ The HCV screening will help 
to identify cases earlier and with the new more effective treatments, these treatments can possibly lead to a cure, which may, over time, lead to a substantial decrease in the number of patients with advanced liver disease. ${ }^{20-22}$

There were some limitations to our study. The exact dates were not available for the year 2005-2009, making it impossible to assess the exact timing of postdischarge outcomes. Second, we may have underestimated postdischarge mortality. This may be due to the LDS denominator files for each calendar year are based on information known to CMS in March of the year following hospitalisations so that some patients without date of death may have been dead but treated as alive. However, $96 \%$ of death dates were validated suggesting that the impact of the 'unvalidated death date' on mortality can be small. The restricted mortality data we had access to did not allow to account for variability in the length of postdischarge follow-up in a survival analysis. As this was a retrospective cohort study, there were unmeasured confounders which we could not adjust for, such as the availability of healthcare providers in patient's place of residence, history of other chronic diseases and major interventions, marital and socioeconomic status, history of substance abuse or psychiatric conditions, metabolic disorders, as well as the results of physical examination and physical activity which may be especially important for appreciating health status of the elderly population. We also could not determine whether patients sought care outside their Medicare plan which potentially may have changed outcomes. ${ }^{23}$

In conclusion, CLD is a common disease entity with important patient and financial outcomes for the Medicare population. Although in-hospital mortality and LOS are decreasing, mortality after discharge remains stable. Also, inpatient and outpatient spending by Medicare is increasing. ${ }^{24}$ Independent demographic and clinical predictors which we identified for payment and clinical outcomes can be used to target resource allocation for prevention. This last point is especially important as the Affordable Care Act (ACA) has begun, ensuring insurance coverage is available to all and patients with pre-existing conditions are not excluded nor do they suffer from lapse in coverage. ${ }^{25}$ It will be imperative to track the impact of the ACA on the longterm outcomes of patients living with CLD especially when one reviews the patients most likely to have CLD are also the patients most likely to be uninsured. Hispanics are the second most prevalent group to be uninsured, especially the young Hispanic male who is working. ${ }^{26}$ In this study, younger Hispanic males were more likely to have CLD than any other group. Therefore, efforts should be directed to ensure this group becomes knowledgeable about the importance and availability of insurance as well as healthy living. Finally, the results are pertinent as the cohort of baby boomers is increasingly eligible for Medicare. Furthermore, the epidemic of obesity will continue to fuel the increasing prevalence of NAFLD and related cirrhosis. As the population of patients with HCV and NAFLD become increasingly eligible for Medicare, the future burden of CLD on Medicare, the most important source of healthcare insurance coverage in the USA will become even more important.

Funding Internal funds only.

Competing interests None.

Ethics approval We obtained institutional review board approval at Inova Fairfax Hospital, and signed a data-use agreement with the CMS.

Provenance and peer review Not commissioned; externally peer reviewed.

Data sharing statement Our data source, Medicare, does not allow sharing of data.

Open Access This is an Open Access article distributed in accordance with the Creative Commons Attribution Non Commercial (CC BY-NC 3.0) license, which permits others to distribute, remix, adapt, build upon this work noncommercially, and license their derivative works on different terms, provided the original work is properly cited and the use is non-commercial. See: http:// creativecommons.org/licenses/by-nc/3.0/

\section{REFERENCES}

1. Gravitz L. Introduction: a smouldering public-health crisis. Nature 2011;474:S2-4.

2. Chak E, Tala AH, Sherman KE, et al. Hepatitis $C$ virus infection in the USA: an estimate of true prevalence. Liver Int 2011;31:1090-101.

3. Ly KN, Xing J, Klevens RM, et al. The increasing burden of mortality from viral hepatitis in the United States between 1999 and 2007. Ann Intern Med 2012;156:271-8.

4. Institute of Medicine. Hepatitis and liver cancer: a national strategy for prevention and control of hepatitis $B$ and $C$. Washington, DC: The National Academies Press, 2010.

5. Thomas DL, Seeff LB. Natural history of hepatitis C. Clin Liver Dis 2005;9:383-98, vi.

6. Lazo M, Hernaez R, Bonekamp S, et al. Non-alcoholic fatty liver disease and mortality among US adults: prospective cohort study. BMJ 2011;343:d6891.

7. Pradat $\mathrm{P}$, Voirin N, Tillmann HL, et al. Progression to cirrhosis in hepatitis $C$ patients: an age-dependent process. Liver Int 2007;27:335-9.

8. Singer ME, Younossi ZM. Cost-effectiveness of screening for hepatitis $C$ virus in asymptomatic, average risk adults: has the time come? Am J Med 2001;111:614-21.

9. Koebnick C, Getahun D, Reynolds K, et al. Trends in nonalcoholic fatty liver disease-related hospitalizations in US children, adolescents, and young adults. J Pediatr Gastroenterol Nutr 2009;48:597-603.

10. Health care spending and the Medicare program. Washington, DC: Published by Medicare Payment Advisory Commission, 2012. http:// medpac.gov/documents/mar12_entirereport.pdf (accessed 9 May 2014).

11. Deyo RA, Cherkin DC, Ciol MA. Adapting a clinical comorbidity index for use with $I C D-9-C M$ administrative databases. J Clin Epidemiol 1992;45:613-61.

12. Lindenauer PK, Lagu T, Shieh MS, et al. Association of diagnostic coding with trends in hospitalizations and mortality of patients with pneumonia, 2003-2009. JAMA 2012;307:1405-13.

13. Yong-Fang K, Goodwin J. Impact of hospitalists on length of stay in the Medicare population: variation by hospital and patient characteristics. J Am Geriatr Soc 2010;58:1649-57.

14. Newhouse JP, Garber AM. Geographic variation in Medicare services. N Engl J Med 2013;368:14651468.

15. Pyenson B, Fitch K, Iwasaki K. Consequences of hepatitis $C$ virus (HCV): costs of a baby boomer epidemic of liver disease. New York: Milliman, Inc, 2009. [Internet, cited 2013 Mar 12]. http://publications. milliman.com/research/health-rr/pdfs/consequences-hepatitis-c-virusRR05-18-09.pdf

16. Wong JB, McQuillan GM, McHutchison JG, et al. Estimating future hepatitis $\mathrm{C}$ morbidity, mortality, and costs in the United States. Am J Public Health 2000;90:1562-9.

17. Coughlin TA, Waidmann TA, Phadera L. Among dual eligibles, identifying the highest-cost individuals could help in crafting more targeted and effective responses. Health Aff (Millwood) 2012;31:1083-91. 
18. Bubolz T, Emerson C, Skinner J. State spending on dual eligibles under age 65 shows variations, evidence of cost shifting from Medicaid to Medicare. Health Aff (Millwood) 2012;31:939-47.

19. Centers for Disease Control. Testing recommendations for chronic Hepatitic C. Obtained from the world wide web at: http://www.cd.gov/ Hepatitis/guidelinsC.htm (accessed 3 Apr 2014).

20. Deuffic-Burban S, Mathurin P, Rosa I, et al. Impact of emerging hepatitis $C$ treatment on future needs for liver transplantation. Dig Liver Dis 2014;46:157-63.

21. Lawitz E, Mangia A, Wyles D, et al. Sofosbuvir for previously untreated chronic hepatitis C infection. N Engl J Med 2013;368:1878-87.

22. Jacobson IM, Gordon SC, Kowdley KV, et al.; POSITRON Study; FUSION Study. Sofosbuvir for hepatitis C genotype 2 or 3 in patients without treatment options. N Engl J Med 2013;368: 1867-77.

23. Quan $\mathrm{H}$, Sundararajanv V, Halfon $\mathrm{P}$, et al. Coding algorithms for defining comorbidities in ICD-9-CM and ICD-10 administrative data. Med Care 2005;43:1073-7.

24. Younossi ZM, Stepanova M, Mishra A, et al. The impact of chronic hepatitis $\mathrm{C}$ on resource utilization and in-patient mortality for Medicare beneficiaries between 2005 and 2010. AP\&T2013;38:1065-75.

25. Medicare Payment Advisory Group. Medicare and Health Care Spending. June 2012. http://www.medpac.gov/documents/ Jun12DataBookEntireReport.pdf (accessed 8 Oct 2013).

26. Centers for Medicare and Medicaid Services. Audience Segmentation for the Emerging Health Care Marketplace. March 22 2013. http://www.marketplace.cms.gov (accessed 8 Oct 2013). 